\title{
Wastewater Treatment and Biofuel Generation Using Algae: An Overview
}

\section{Shirjeel Ahmad Siddiqui*}

Department of Agricultural Microbiology, Aligarh Muslim University, Aligarh, India

*Corresponding Author: Shirjeel Ahmad Siddiqui, Department of Agricultural

Microbiology, Aligarh Muslim University, Aligarh, India.
Received: July 26, 2021

Published: September 15, 2021

(C) All rights are reserved by Shirjeel Ahmad Siddiqui.

\section{Abstract}

A large number of organic and inorganic substances are released in the environment on daily basis due to human activities; the waste could be of domestic, agricultural or industrial origin. When the waste is in the form of sewage either of industries or that originated from domestic and agricultural practices, it is needed to be treated before its discharge or disposal into the environment because such a practice can cause serious health issues to humans and a severe damage to flora, fauna and biodiversity. As a remedy, wastewater treatment plants have been in use from about 150 years which treats the sewage for its further safer discharge in the water bodies. Wastewater Treatment plants are run and controlled by the governing bodies on a very large scale and are also setup in industries for treating industrial effluents.

Microorganisms are widely used in treatment of wastewater during secondary and tertiary treatment process and mainly involve species of bacteria and fungi. In this review, the use of algae in wastewater treatment has been described and it also focuses on how biofuels can be generated using the same.

Keywords: Wastewater Treatment; Algae; Biofuel

\section{Introduction}

Wastewater Treatment has been in practice from $19^{\text {th }}$ century and it has served mankind in many ways like in the maintenance of ecological balance and biodiversity and also helped in reducing a number of diseases which are caused by consumption of untreated wastewater [1]. Various modifications have been done in Wastewater Treatment processes till now which includes use of latest technology and methods for developing high efficiency in less time, use of more potent microorganisms during the process etc. [2]. Algae use wastewater as a substrate and grow efficiently on it. Algae feed over the nutrient content of sewage and gives clear water as a result. It efficiently removes nutrients from the wastewater which otherwise is tedious process moreover species of bacteria and fungi are comparatively reported to be slow in performing this action [3]. Microalgae are known to sequester heavy metals [4].
The most important aspect is that algae being photoautotrophs and rich in lipid and carbohydrate content can be exploited for generation of biofuels simultaneously during Wastewater Treatment. It can be done either by using photobioreactors or growing algae in open system during Wastewater Treatment [1].

It is evident that fossil based fuels are going to exhaust in the near future. Besides that, the excessive use of fossil fuels is leading to environmental imbalances as the burning of such fuels release by-products of carbonaceous compounds and other complex constituents of nitrogen and sulfur in the environment which gives rise to problems like air pollution, acid rain and global warming to name a few. An alternative approach to reduce the impact of such environmental problems lies in using biological based fuels or biofuels [5]. 
Second generation biofuels are in use nowadays, the use of algae based biofuels can give rise to next generation biofuels. Moreover to it, the algal based biofuels can easily be generated while using algae in Wastewater Treatment. In this way algae can be exploited for multiple uses at a same time whether it is in treating of wastewater or generation of biofuels or its extended use in removal of nutrients and heavy metal contamination from wastewater

\section{Basic methodology involved}

While using algae for treating wastewater and further utilizing its biomass for biofuel production, the very first step is to cultivate the algae in wastewater followed by harvesting

\section{Cultivation of algae}

For the proper growth and development of algae it requires carbon source, light energy, and a regulated $\mathrm{pH}$ and temperature. In the wastewater the algae feeds upon organic matter to get carbon source and it also derives nitrogen and phosphorous from wastewater thus preventing eutrophication.

The methods for cultivation of algae should be adopted in a manner in which a large amount of lipids can be generated from algal biomass and that too in low cost [6]. It means that the cultivation method should be productive, efficient and economic. Two types of systems are used for cultivation of algae; open system and closed system [7].

\section{Open system}

These are the most common cultivation systems used for large scale production of algal biomass nowadays, commonly called as High Rate Algal Ponds (HRAPs) or raceway ponds. These systems are mostly used for integrative approach of wastewater treatment and biofuel production $[8,9]$. The open ponds or the raceway ponds consist of a paddle wheel for proper mixing of algae and nutrients. These systems are quite inexpensive but are subjected to contamination and low productivity mainly due to poor supply of carbon dioxide, loss of vapor etc. In open systems it is highly difficult to maintain temperature, $\mathrm{pH}$ and intensity of light reaching to ponds.

\section{Closed system}

The closed system involves the use of photobioreactors. In comparison to open system, closed system provides more productivity, reduced risk of contamination, proper maintenance of tempera-

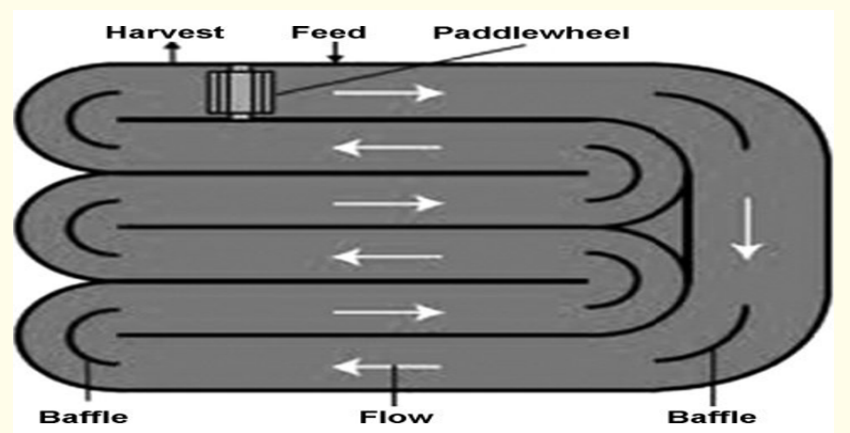

Figure 1: Illustration of raceway pond (Singh., et al. 2013).

ture and $\mathrm{pH}$ and allows greater fixation of $\mathrm{CO}_{2}[10,11]$. But these systems have high maintenance and material costs and often cases of toxic accumulation of oxygen have been reported which causes decrease in productivity as a result.

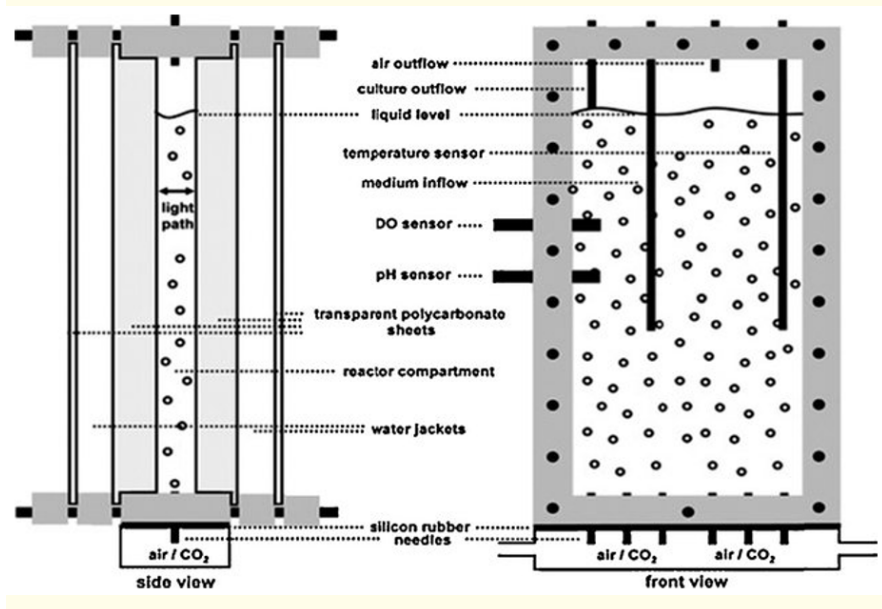

Figure 2: Illustration of a photobioreactor (Singh., et al. 2013).

\section{Harvesting}

For production of biofuels from algae, a large amount of biomass is needed. Proper harvesting methods should be deployed in order to generate high yield of biomass efficiently. Harvesting of algal cells can be done by mechanical, chemical or even biological based method, but the most common methods being used today 
are centrifugation, sedimentation, flocculation, floatation and filtration [12]. Centrifugation and filtration are the most preferred method of harvesting for separation and collection of biomass.

\section{Outcomes}

\section{Treated wastewater}

The algae feed upon on the waste present in wastewater and degrade organic compounds with the help of other bacterial population. Since, algae is a photosynthetic organism it uptakes carbon dioxide released by degradation of organic compounds and also releases oxygen in wastewater, in this manner algae decreases Biological Oxygen Demand of water [13]. The algae treated water is further subjected to final treatment which includes disinfection with Chlorine and treatment with UV. Algae are also known to serve other benefits during wastewater treatment process; these include - removal of heavy metals, coliform bacteria, nutrients mainly $\mathrm{Ni}$ trogen and Phosphorous from wastewater [14]. Algae also reduce Chemical Oxygen Demand of wastewater.

\section{Biofuel production}

The biomass obtained during treatment of wastewater can be used in a number of ways for production of biofuels. The products that are mainly generated as biofuels are biodiesel, bioethanol, biohydrogen, and biogas. Besides that, other products like bio-oil, syngas and bioelectricity can also be obtained [9,15-16]. The biomass is converted to biofuels either through thermochemical breakdown or by biochemical means and transesterification.

\section{Thermochemical conversion}

The process involves the principle of thermal decomposition of biomass to extract fuel products. The process can be further subcategorized into gasification, thermal liquefaction and pyrolysis $[1,17]$.

- Gasification involves conversion of biomass into carbonaceous gas i.e. syngas.

- Thermal liquefaction is the process in which the biomass is liquefied and heated and further converted into small molecules with high energy which can be exploited in extraction of bio-oil.

- In the process of pyrolysis, biomass is heated in absence of oxygen and algal based charcoal as well as bio-oil can be obtained.

\section{Biochemical conversion}

It includes biological processing and conversion of biomass to generate biofuels. Examples of biochemical conversion processes include anaerobic digestion, alcoholic fermentation and photobiological hydrogen production $[18,19]$. In case of anaerobic digestion process, the algal biomass is treated anaerobically in fermenters and biogas can be generated through this process [20]. Due to increase in cost of fossil based energy fuel anaerobic digestion products are in demand nowadays.

- The process of alcoholic fermentation is the same which is used in industries for production of ethanol by using yeast in this case algal biomass is used and bioethanol is generated [21].

- The process of photobiological hydrogen production involves the conversion of water into hydrogen and oxygen ions by algae. The algae are grown in normal conditions with all the proper requirements; suddenly the environment is changed into anaerobic condition [22]. This sudden change in conditions leads to production of oxygen and hydrogen by algae and in this way biohydrogen can be obtained.

\section{Transesterification}

It is the reaction of triglycerides with alcohol in the presence of a catalyst to produce fatty acid chains and glycerol. Fatty Acid Methyl Ester (FAME) can be produced by using ethanol/methanol. In this process the biomass being rich in lipids and oil is subjected to the process of transesterification in the presence of a strong catalyst like an acid or base and as a result long chain of fatty acids are produced that are rich in energy and can be used as biodiesel with a few catalytic modification and glycerol is obtained as a byproduct.

\section{Discussion}

Waste water commonly called as sewage or the liquid waste is the water that mainly arises from domestic, industrial or agricultural practices. It also includes bio-medical wastes from hospitals, clinics or other healthcare sectors [1,23-25]. Wastes generated from laboratories of research centers also contribute to the sewage. The sewage contains a large number of organic and inorganic substances as well as other solid wastes and materials. The composition of wastewater may vary from place to place depending upon the sources from which the waste is generated [26]. The wastewater when discharged directly into water bodies like rivers, lakes, streams, estuaries etc. can cause serious threats to the biodiversity and results in water pollution [27]. It disrupts the ecosystem and interferes with the ecological balance of the nature. Moreover to it if this water is consumed for human use, it turns out to be lethal for them as the untreated water contains severe toxic chemicals and compounds which when consumed by humans can cause various types of diseases, disorders, mutations and even cancer [28]. So in 
order to avoid all such conditions Wastewater Treatment is done which treats the water to such extent that it becomes consumable and can be easily discharged into water bodies [29].

Algae have been in use for treatment of wastewater from about four decades. A lot of work has been done in finding the role of algae in removal of nutrients and also in removal of heavy-metals from wastewater as well as pathogens and other contaminants from wastewater [30]. Bio-treatment with microalgae is particularly attractive because of their photosynthetic capabilities, converting solar energy into useful biomass which can be exploited for production of biofuels [31,32]. The algae can treat municipal waste, industrial waste as well as agricultural waste and it utilizes wastewater as a substrate for growth by feeding over organic content and nutrients present in it [33]. The algae for wastewater treatment may be indigenously present within the wastewater or can be added into the wastewater from laboratory or any other natural source. Various species of algae have been reported in treatment of wastewater as well as in production of biofuels but independently. The most promising species of algae reported for integrated approach of wastewater treatment with biofuel production includes Chlorella sp. and Spirulina sp. as well $[30,34]$.

\section{Limitations and Areas of Improvement}

Most of the work on algae based biofuels has been confined to laboratory scale only, including the field trials conducted as a part of experiment. There is a need for finding more viable and efficient species of algae for carrying out this process, only one or two species are in use today for generation of biofuels integrated with wastewater. Although cultivation and harvesting algae is quite economic process but conversion of biomass to biofuels increases the cost of process to several folds, this must be reduced so as to make it available to common people.

Research at fundamental and field-scale will assist optimization of harvestable algal yield and thus further improve the economic viability and the full-scale implementation of biofuel production from wastewater treatment systems. Overcoming these challenges will be a beneficial aspect in production of biofuels as well as in treating of wastewater.

Although biofuel generation using algae during wastewater is a successful approach but it has certain aspects which are needed to be overcome in order to make the process more efficient and economic, these approaches are
- Design of more regulated and controlled culture system which can overcome the demerits of open as well as closed system

- $\quad$ Proper investigations and experiments should be performed in order to find more viable and productive species.

- Genetic engineering technology can be used for making hybrid strains which can generate higher yields.

\section{Conclusions}

Wastewater treatment using algae is presently the only viable way to produce algal biomass for conversion to biofuels with minimum resources. Algae contain about $50 \%$ of their weight in form of carbohydrates and oil. Algae can be grown almost anywhere including the sewage or even salt water and does not require fertile land. Moreover, processing doesn't involve any special requirements. Reactors for algal cultures are open ponds photobioreactors and closed systems. Algae are very important as a biomass source. They can also be used for removal of nutrients and heavy metals from the wastewater.

\section{Bibliography}

1. Abdel-Raouf N., et al. "Microalgae and wastewater treatment". Saudi Journal of Biological Sciences 19.3 (2012): 257-275.

2. Amenorfenyo DK., et al. "Microalgae Brewery Wastewater Treatment: Potentials, Benefits and the Challenges". International Journal of Environmental Research and Public Health 16.11 (2019): 1910.

3. Barbara J S. "The false promise of biofuels". Special Report from the International Forum on Globalization and the Institute for Policy Studies (2007).

4. Batten D., et al. "Using wastewater and high-rate algal ponds for nutrient removal and the production of bioenergy and biofuels". Water Science and Technology 67.4 (2013): 915-924.

5. García J., et al. "Long term diurnal variations in contaminant removal in high rate ponds treating urban wastewater". Bioresource Technology 97 (2006): 1709-1715.

6. Doucha J and Livansky K. "Outdoor open thin-layer microalgal photobioreactor: potential productivity". Journal of Applied Phycology 21 (2009): 111-117.

7. Craggs RJ., et al. "Algal biofuels from wastewater treatment high rate algal ponds". Water Science and Technology 63.4 (2011): 660 . 
8. Hwang JH., et al. "Use of microalgae for advanced wastewater treatment and sustainable bioenergy generation". Environmental Engineering Science 33.11 (2016): 882-897.

9. Park H and Lee CG. "Theoretical calculations on the feasibility of microalgal biofuels: utilization of marine resources could help realizing the potential of microalgae". Biotechnology Journal 11.11 (2016): 1461-1470.

10. Roberts DA., et al. "The effect of $\mathrm{CO} 2$ on algal growth in industrial waste water for bioenergy and bioremediation applications". PloS one 8.11 (2013).

11. Mudhoo A., et al. "Removal of heavy metals by biosorption". Environmental Chemistry Letters 10.2 (2012): 109-117.

12. Show PL., et al. "A holistic approach to managing microalgae for biofuel applications". International Journal of Molecular Sciences 18.1 (2017): 215.

13. Chew KW., et al. "Microalgae biorefinery: high value products perspectives". Bioresource Technology 1.229 (2017): 53-62.

14. Su Y., et al. "Municipal wastewater treatment and biomass accumulation with a wastewater-born and settleable algal-bacterial culture". Water Research 45.11 (2011): 3351-3358.

15. Park JB., et al. "Wastewater treatment high rate algal ponds for biofuel production". Bioresource Technology 102.1 (2011): 3542.

16. Satyanarayana T., et al. "Microorganisms in sustainable agriculture and biotechnology". Springer Science and Business Media (2012).

17. Hannon M., et al. "Biofuels from algae: challenges and potential". Biofuels 1.5 (2010): 763-784.

18. Tiron 0., et al. "Overcoming microalgae harvesting barrier by activated algae granules". Scientific Reports 7.1 (2017): 1-1.

19. Eriksson E., et al. "Household chemicals and personal care products as sources for xenobiotic organic compounds in grey wastewater". Water Sa 29.2 (2003): 135-146.

20. Popp J., et al. "Biofuels and their co-products as livestock feed: global economic and environmental implications". Molecules 21.3 (2016): 285.

21. Mata TM., et al. "Microalgae for biodiesel production and other applications: a review". Renewable and Sustainable Energy Reviews 14 (2010): 217-232.
22. Shahidi F. "Nutraceuticals and specialty lipids and their coproducts". CRS Series 5 (2005).

23. Bhatt NC., et al. "Coupling of algal biofuel production with wastewater". The Scientific World Journal (2014).

24. Christenson L and Sims R. "Production and harvesting of microalgae for wastewater treatment, biofuels, and bioproducts". Biotechnology Advances 29.6 (2011): 686-702.

25. Demirbas A. "Use of algae as biofuel sources". Energy Conversion and Management 51.12 (2010): 2738-2749.

26. Kheshgi HS., et al. "The Potential of Biomass Fuels in the Context of Global Climate Change: Focus on Transportation Fuels". Annual Review of Environment and Resources 25 (2000): 199244.

27. Khotimchenko S V., et al. "Lipid composition of the red alga Tichocarpus crinitus exposed to different levels of photon irradiance". Phytochemistry 66 (2005): 73-79.

28. Keem YK and Low CS. "Productivity of outdoor algal cultures in enclosed tubular photobioreactor". Journal of Biotechnology and Bioengineering 40 (1992): 1110-1122.

29. Wunder K., et al. "Algae for wastewater treatment: clean water, nutrient recovery and gaining biomass" (2015).

30. Wang L., et al. "Cultivation of green algae Chlorella sp. in different wastewaters from municipal wastewater treatment plant". Applied Biochemistry and Biotechnology 162.4 (2010): 11741186.

31. Andersson V., et al. "Algae-based biofuel production as part of an industrial cluster". Biomass and Bioenergy 1.71 (2014): 113-124.

32. Kheshgi HS., et al. "The Potential of Biomass Fuels in the Context of Global Climate Change: Focus on Transportation Fuels". Annual Review of Environment and Resources 25 (2000): 199244.

33. Asveld L. "The need for governance by experimentation: The case of biofuels". Science and Engineering Ethics 22.3 (2016): 815-830.

34. Tiron 0., et al. "Overcoming microalgae harvesting barrier by activated algae granules". Scientific Reports 7.1 (2017): 1-1.

Volume 4 Issue 10 October 2021

(C) All rights are reserved by Shirjeel Ahmad Siddiqui. 